\title{
ESTUDO DE CASO: IDENTIFICAÇÃO DE MANIFESTACÖES PATOLOGICAS COM O USO DA TERMOGRAFIA INFRAVERMELHA
}

\author{
OLIVEIRA, JOSÉ LUCAS PESSOA DE \\ Professor \\ IFPB - Campus Cajazeiras \\ Paraíba; Brasil \\ lucaspessoa.engcivil@gmail.com
}

FORMIGA, ANDRESSA PER
Estudante de graduação
IFPB - Campus Cajazeiras
Paraíba; Brasil
andressaformigg@gmail.com

\author{
DIAS, LEONARDO DE SOUZA \\ Engenheiro Civil \\ IFPB - Campus Cajazeiras \\ Paraíba; Brasil \\ dias.leonardo@academico.ifpb.edu.br
}

\author{
JOSUÉ, JOSEFA LUANA BARBOSA \\ Estudante de graduação \\ IFPB - Campus Cajazeiras \\ Paraíba; Brasil \\ luanajosueec@gmail.com
}

\section{RESUMO}

As edificações vêm sofrendo com manifestações patológicas a muito tempo, as técnicas e materiais de construções mudaram bastante, e com isso, as ferramentas de avaliação e inspeção das edificações também tiveram sua evolução tecnológica. Uma técnica que surgiu e tem ganhando bastante atenção dos profissionais da engenharia, é a Termografia Infravermelha (TI), que se baseia na formação de imagens térmicas (termogramas) obtidas pelos aparelhos (termógrafos), por meio da radiação infravermelha emitida pelos objetos. A partir da variação de temperatura observada no gradiente de cor do aparelho, é possível identificar regiões com anomalias (variações térmicas fora do esperado para o local), que podem se configurar como uma Manifestação Patológica (MP). Esse ensaio não destrutivo pode identificar presença de umidade nos elementos construtivos, falhas de uniformidade na superfície de revestimentos, aquecimento excessivo em dispositivos elétricos, vazamentos em tubulações etc. O trabalho pretende mapear locais com manifestações patológicas em uma edificação pública da rede de ensino na cidade de Cajazeiras-PB, com auxílio do termógrafo infravermelho modelo FLIR i7. O uso da TI se mostrou eficiente para identificar regiões com anomalias que não seriam facilmente identificadas e quantificadas a olho nu. A técnica é simples de ser empregada, auxilia na redução de tempo e custo nos serviços de manutenção predial. O termógrafo torna o trabalho do profIssional da engenharia mais preciso e eficiente. Sob a ótica da sustentabilidade ambiental auxilia na redução dos resíduos de demolição que seriam gerados em intervenções desnecessárias para a solução do problema.

Palavras-chave: Termografia Infravermelha, patologias, umidade, edificações públicas.

\section{ABSTRACT}

Buildings have been suffering from pathological manifestations for a long time, construction techniques and materials have changed a lot, and with this, the tools for assessment and inspection of buildings have also had their technological evolution. A technique that has emerged and has been gaining a lot of attention from engineering professionals, is the Infrared Thermography (TI), which is based on the formation of thermal images (thermograms) obtained by the devices (thermographs), through the infrared radiation emitted by the objects. From the temperature variation observed in the color gradient of the device, it is possible to identify regions with anomalies (thermal variations outside the expected for the location), which can be configured as a Pathological Manifestation (MP). This non-destructive test can identify the presence of moisture in the building elements, uniformity flaws in the surface of coatings, excessive heating in electrical devices, leaks in pipes, etc. The work intends to map places with pathological manifestations in a public school building in the city of Cajazeiras-PB, with the aid of the infrared thermograph model FLIR i7. The use of IT proved to be efficient in identifying regions with anomalies that would not be easily identified and quantified with the naked eye. The technique is simple to use, it helps to reduce time and cost in building maintenance services. The thermograph makes the engineering professional's job more accurate and efficient. From the perspective of environmental sustainability, it helps to reduce demolition waste that would be generated in unnecessary interventions to solve the problem.

Keywords: Infrared thermography, pathologies, humidity, public buildings. 


\section{INTRODUÇÃO}

Todos os elementos presente na natureza possuem um ciclo de vida definido, no contexto da engenharia também é preciso se preocupar com a vida útil dos componentes e dos materiais que serão utilizados na edificação antes de iniciar sua execução, sendo um cuidado que deve partir desde a concepção dos projetos nas suas mais variadas disciplinas. A realização de manutenções periódicas durante a fase de utilização de uma edificação também é fundamental para se atingir a vida útil especificada em projeto.

As manutenções preventivas quando são negligenciadas, acabam por gerar desconforto no médio e longo prazo aos usuários além de prejuízos financeiros. Uma vez que, pequenos problemas que poderiam ser identificados e sanados facilmente durante as manutenções preventivas, com o tempo, acabam atingindo proporções cada maiores, até apresentar as primeiras MPs. Quando maior for tempo para identificar as causas do problema, maiores serão as dificuldades para solucionar o mesmo, em alguns casos, acaba sendo mais viável reconstruir totalmente o trecho ou parte com problemas.

A TI apareceu para a construção civil como uma ferramenta de auxílio para os profissionais da área como engenheiros patologistas, avaliadores de imóveis, pesquisadores e peritos. Considerada como um ensaio não destrutivo, a técnica é simples e prática de ser aplicada, no mercado é encontrado um serie de modelos de câmeras termográficas portáteis. Essa ferramenta é capaz de identificar a radiação infravermelha emitida pelos materiais, e nas imagens termográficas geradas pelos aparelhos, é apresentado uma escala de cores em função do gradiente de temperatura observado pelo aparelho.

Para uma correta aplicação dessa tecnologia é preciso estabelecer critérios e padrões que permitam os profissionais identificarem as anomalias com segurança. A técnica possui grande potencialidade, principalmente para identificações de anomalias, devido a agilidade e simplicidade nas inspeções, possuindo um leque significativo de possíveis outras novas aplicações (BAUER; PAVÓN, 2015, p. 93).

\section{TERMOGRAFIA INFRAVERMELHA}

\subsection{Princípios da técnica}

A termografia é uma técnica de inspeção não destrutiva e não invasiva que tem como base a detecção da radiação infravermelha emitida naturalmente pelos corpos com intensidade proporcional à sua temperatura. Através dessa técnica é possível identificar regiões, ou pontos, onde a temperatura está alterada com relação a um padrão preestabelecido. É baseada na medida da radiação eletromagnética emitida por um corpo a uma temperatura acima do zero absoluto (BAUER, 2013).

Segundo Mendonça, Amaral e Catarino (2013), todos os objetos emitem radiação infravermelha. A intensidade da radiação emitida depende de dois fatores: da temperatura do objeto e da capacidade do objeto de emitir radiação. Está última é definida como emissividade $(\varepsilon)$. Ou seja, é a capacidade que o material tem para radiar energia comparada com a de um "corpo negro perfeito" (o qual apresenta $\varepsilon=1$ ). Um corpo negro perfeito é um corpo que absorve toda a luz recebida e não reflete nenhuma. Sabe-se que todos os materiais com uma temperatura acima do zero absoluto $\left(-273^{\circ} \mathrm{C}\right)$ radiam calor. A radiação de calor significa o mesmo que radiação infravermelha. Quanto mais quente está o objeto, maior será a radiação.

Segundo Brioschi (2008), o estudo da radiação infravermelha, começou primeiramente com os experimentos ópticos de Della Porta no final do século XVI. Dois séculos mais tarde Sir Willian Herschel, usando um espectroscópio, descobriu que o sol emitia raios infravermelhos. Esta descoberta e sua relação com a luz não se tornaram claras até a metade do século XIX, quando o filho de Herschel, John Herschel, um pioneiro no campo da fotografia, produziu em papel, a primeira termografia. Após a Segunda Guerra Mundial, a tecnologia de radiação infravermelha avançou, mas era restrita para uso militar.

Bauer e Pavón (2015) compara a termografia ao ensaio de ultrassom, em que, nesse último a velocidade da onda muda em decorrência de defeitos internos no interior do elemento. No caso da inspeção termográfica, os defeitos também causam uma perturbação, só que no fluxo de calor (entre o elemento e o meio ambiente).

\subsection{Aplicação na construção civil}


Essa tecnologia pode ser usada para caracterizar e localizar a origem das MPs visíveis, como também pode ser utilizada para a identificação de patologias que ainda não são visíveis a olho nu, ainda em fases embrionárias. São geradas fotos do local (termogramas), onde a câmera apresenta as temperaturas ao longo da área indicada. Com os resultados em mãos, é possível orientar medidas adequadas para prevenção ou correção do problema (MENDONÇA; AMARAL; CATARINO; 2013, p. 6).

O ensaio é bastante indicado para identificar patologias oriundas da presença de umidade em elementos ou partes de uma construção. A presença de água altera a condutividade térmica do material de construção, podendo alterar também a temperatura de superfície do material de construção devido a refrigeração causada pela evaporação da água. Embora a termografia não detecte diretamente a presença de fungos, a mesma poderá ser utilizada para identificação de umidade em locais que haja seu desenvolvimento, pois a proliferação desses microrganismos requer temperaturas entre $+4 \mathrm{e}+38^{\circ} \mathrm{C}$ (FLYR SYSTEMS, 2010).

Segundo Bauer e Pavón (2015), é necessário empregar técnicas que permitam conhecer, identificar e avaliar os materiais empregados na construção civil. Para investigação, é usado em alguns casos técnicas não destrutivas, que permitem inferir sobre causas, comportamentos e anomalias, bem como identificar e mapear regiões de danos nas estruturas e demais sistemas dos edifícios. A termografia vem ao encontro dessa necessidade, pois é um método não destrutivo para estabelecer índices e parâmetros que contribua com a realização das inspeções, de forma rápida e mais eficiente.

Takeda e Mazer (2018) fizeram uma avaliação de MPs em fachadas de edificações com o uso da termografia, relata que os resultados ao serem confrontados com ensaios de percussão nos revestimentos e vistorias in-loco, confirmaram a viabilidade da termografia como ensaio não destrutivo aplicável na inspeção, bem como para identificar a sua real extensão. Com grande potencial de utilização devido a sua agilidade e confiabilidade quando comparadas a técnicas usuais, diminuindo a subjetividade nas inspeções e eliminando riscos de segurança para trabalhos em altura.

Talvez o impacto mais significativo que a termográfica cause na construção civil seja o fato de permitir avaliações com relativa precisão, sem a necessidade de haver contato físico com o local em questão, além disso, pode acabar eliminando intervenções que seriam danosas a integridade a edificação.

A medição do infravermelho trouxe vantagens na possibilidade de fazer medições de temperaturas a longas distâncias, sem haver contato físico, de objetos móveis, de objetos com difíceis acesso ou ainda objetos em ambientes perigosos (BARREIRA, 2004).

\section{METODOLOGIA}

Foi realizado inicialmente uma inspeção visual buscando percorrer todo o conjunto educacional, buscando pontos críticos e passiveis de ocorrência de MP. Em seguida iniciou-se a realização do ensaio, utilizando-se o termógrafo infravermelho Flir i7 (Figura 1).

O aparelho é portátil e pode ser manuseado de forma bastante simples, sendo possível fazer imagens termográficas das superfícies dos objetos, que podem ser armazenadas em um cartão de memória. O aparelho pode ser configurado de algumas formas, no caso aqui analisado, a imagem termográfica apresenta uma legenda com a indicação da escala do gradiente térmico (na horizontal), indicando a temperatura mínima e máxima observada naquele instante, além disso, é possível observar também no canto superior esquerdo do termograma a temperatura que é medida no ponto central, que é destacado na imagem pelo símbolo de "+" com um círculo central.

O local ensaiado é composto por vários blocos, utilizados como salas de aula, salas administrativas, laboratórios, almoxarifado, auditórios, biblioteca, refeitórios, cantina, quadra de esportes etc. A maioria dos blocos foram construídos a pelo menos 20 anos, não se buscou registro de manutenções realizadas em épocas passadas. A tipologia construtiva das edificações é composta por estruturas aporticadas em concreto armado, com alvenarias de vedação em blocos cerâmicos vazados ou em blocos cerâmicos maciços, o revestimento externo é constituído em sua maioria por plaquetas cerâmicas simulando tijolos aparentes (porosos). 


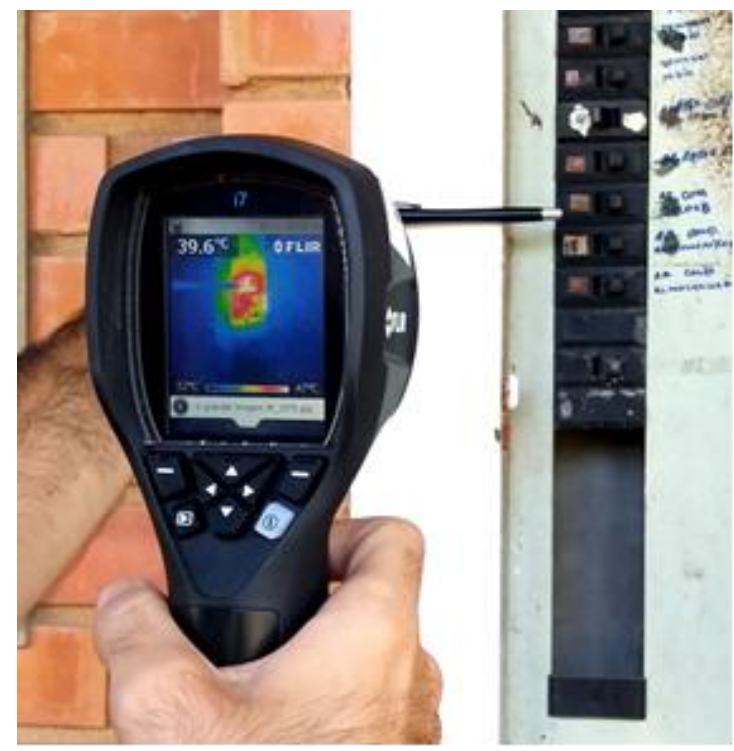

Figura 1: Termografo Infravermelho Flir i7.

A cidade de Cajazeiras-PB ao qual se localiza o ambiente escolar analisado possui um clima semiárido, com temperaturas elavas e baixa umidade do ar durante a maior parte do ano, as precipitações pluviométricas ocorrem de forma bastante irregular e normalmente entre janeiro a maio. O ensaio foi realizado fora do período de chuvas.

Houve o cuidado de realizar o ensaio no período da manhã e tarde, nos horários mais quentes do dia, para que as anomalias observadas no aparelho pudessem ser mais facilmente identificadas. Conforme orienta o Manual do Usuário da Flir Systems (2010), os defeitos de construção relacionados com a umidade e os danos provocados por água poderão surgir apenas quando tiver sido aplicado calor na superfície, por exemplo, calor do sol.

Após todo o levantamento fotográfico, houve uma seleção e agrupamento das MPs observadas para uma melhor compreensão da problemática. Em seguida, foi escolhido os casos mais críticos de cada situação para uma posterior análise física do local, observando visualmente os pontos críticos para tentar relacioná-los as anomalias observadas no aparelho.

\section{RESULTADOS E DISCUSSÕES}

Para melhor compreensão das MPs, decidiu-se resumir as anomalias observadas com o termógrafo, em seis situações distintas, as quais ocorrem com maior frequência no ambiente em análise. Vale ressaltar que o conjunto educacional é formado por várias edificações, sendo que algumas manifestações patológicas são recorrentes em vários locais, como é o caso da presença de bolor, lodo e eflorescências nas alvenarias de vedação. Em sua maioria ocorrendo devido a umidade oriunda em alguns casos do solo e em outros devido a vazamento em tubulações.

A seguir será apresentado os termogramas obtidos com o aparelho, em conjunto com fotografias reais do local, bem como comentários a respeito da avaliação qualitativa do que foi observado na avaliação in-loco.

\subsection{Vazamento em tubulações}

O caso apresentado na Figura 2, é referente a pontos de vazamento em um trecho de tubulação localizado em um bloco administrativo. Na região inferior e superior da tubulação é observado uma variação de temperatura de $7^{\circ} \mathrm{C}$ e $6{ }^{\circ} \mathrm{C}$, respectivamente. É possível identificar com bastante facilidade os pontos mais frios (cor azul), ao qual indica a presença de umidade. $\mathrm{O}$ termógrafo está indicando que a região úmida está com uma temperatura na ordem de $+27^{\circ} \mathrm{C}$, abaixo da temperatura média dos elementos ao seu redor. 


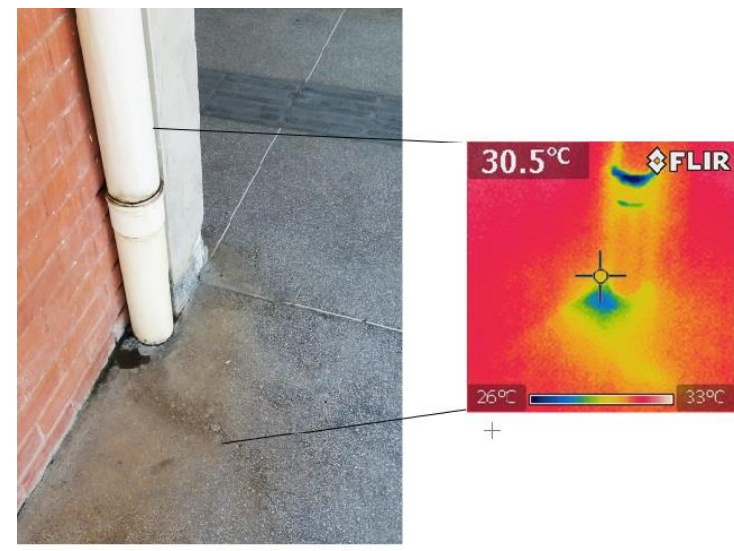

a) Trecho Inferior da tubulação

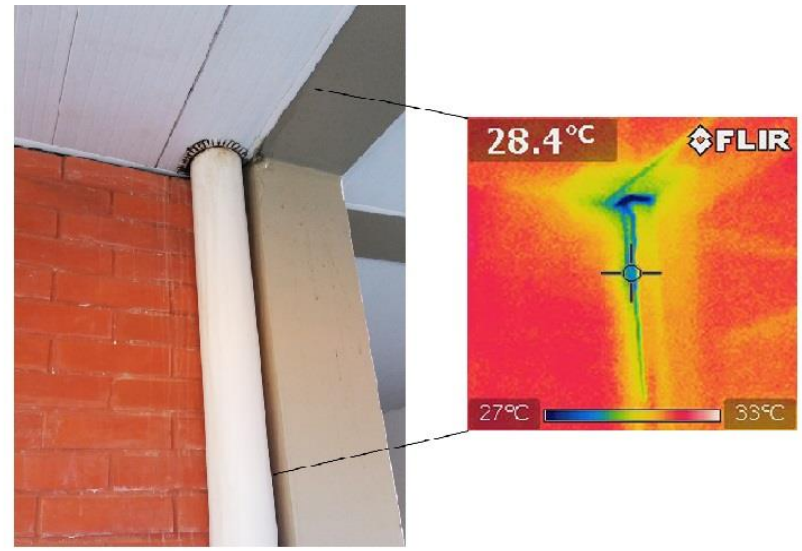

b) Trecho superior da tubulação

Figura 2: Vazamento em trecho de tubulação.

$\mathrm{Na}$ vistoria in-loco da tubulação é possível identificar que exatamente no ponto de conexão das duas tubulações (Figura 2 (a)) havia a presença de lodo, o mesmo ocorre na região superior de encontro com o forro (Figura 2 (b)), indicando que a presença de umidade é constante nesses locais. Isso corrobora com as imagens termográficas, onde foi possível indicar exatamente o local do problema. Nota-se que na região da alvenaria que está em torno da tubulação existe manchas esbranquiçadas que são características de eflorescências, provavelmente devido ao vazamento presente no local.

\subsection{Aquecimento em circuitos elétricos}

Os circuitos de uma instalação elétrica devem ser dimensionados e distribuídos com cargas o mais equilibradas possíveis, para evitar problemas com sobrecarga. Os dispositivos elétricos costumam gerar bastante calor ao estarem em funcionamento, na Figura 3 é mostrado dois Quadros de Distribuição (QD) da rede elétrica de um dos blocos de sala de aula, onde é possível identificar um gradiente de temperatura relativamente alto (com variação na ordem de $26{ }^{\circ} \mathrm{C}$ ).

No QD do Bloco 01 (Figura 3 (a)) é evidente que há um desbalanceamento das fases indicado pela notável diferença de temperatura entre os condutores que se conectam aos disjuntores. $\mathrm{O}$ condutor do primeiro disjuntor (indicado na imagem pela letra A) está com uma temperatura próxima dos $+60^{\circ} \mathrm{C}$, enquanto os demais apresentam temperaturas mais baixas, entre $7{ }^{\circ} \mathrm{C}$ e $10^{\circ} \mathrm{C}$ a menos.

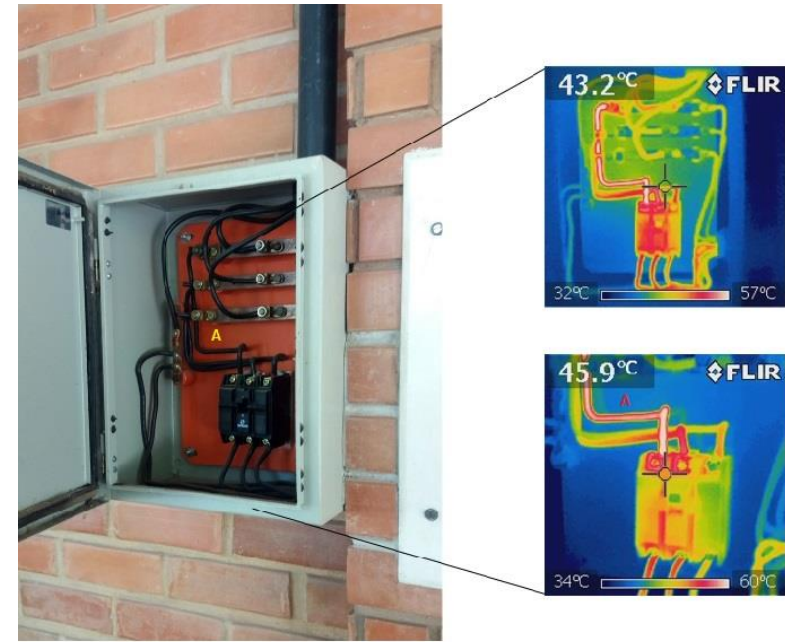

a) Quadro de distribuição do Bloco 01

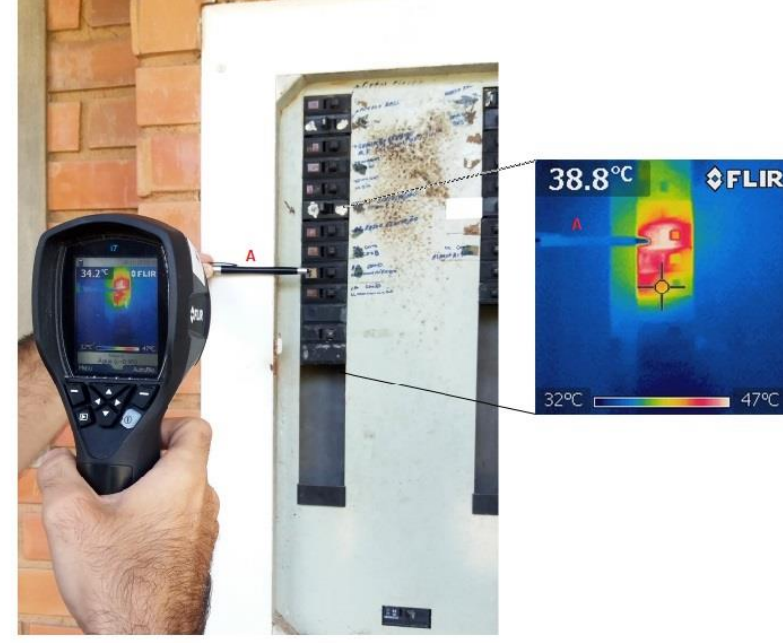

b) Quadro de distribuição do Bloco 02

Figura 3: Quadros de Distribuição com pontos de aquecimento. 


\subsection{Umidade ascendente do solo}

Na Figura 4, foi constatado que em toda a região inferior da alvenaria de vedação externa de um dos blocos de laboratórios está com presença de umidade. Possivelmente essa umidade seja oriunda do solo, conseguindo ascender até alturas na ordem de $30 \mathrm{~cm}$, e nos pontos de encontro da alvenaria com os pilares, é um pouco mais intensa, superior a $50 \mathrm{~cm}$. Vale destacar que no trecho final da alvenaria (canto superior esquerdo da imagem) há também a presença de uma torneira externa que apresenta vazamento, com isso intensificando a umidade naquela região. A falta de estanqueidade das tubulações pode ter sido a causa da umidade do solo presente nesse local.

Por se tratar de uma região externa em local ensolarado, a temperatura média do local estava relativamente alta, porém, é possível notar uma temperatura mais baixa, na ordem de $+29^{\circ} \mathrm{C}$, na parte inferior da alvenaria.

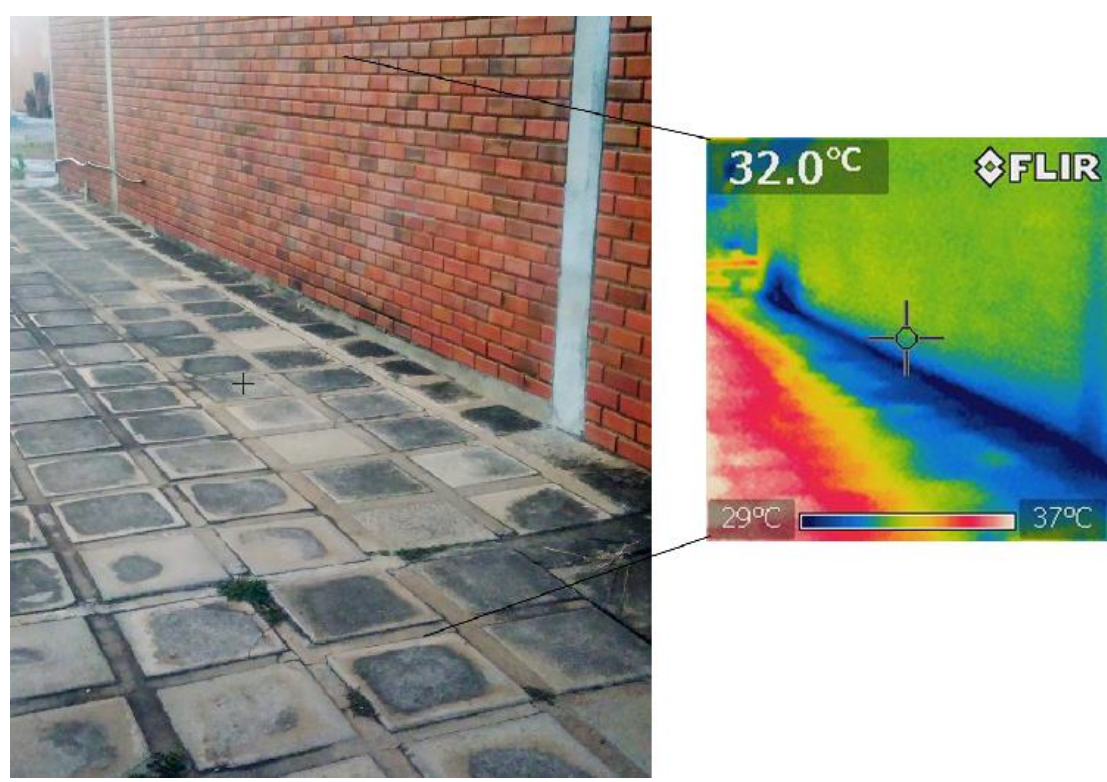

Figura 4: Alvenaria de vedação externa com presença de umidade ascendente.

É um caso bastante recorrente em diversos locais, a presença de umidade na região inferior (primeiras fiadas) das alvenarias de vedação, normalmente são seguidas de manchas de eflorescências e bolor. Essa situação é típica de umidade ascendente do solo, em locais onde há falha na impermeabilização que permite o contato direto do solo úmido com a alvenaria, e por meio do fenômeno da capilaridade, a água consegue percolar pelos microporos da alvenaria até atingir certas alturas, normalmente inferior a um metro de altura.

\subsection{Anomalias em revestimentos cerâmicos}

A termografia também pode ser usada para avaliar anomalias em revestimentos cerâmicos, como no caso apresentado na Figura 5, que mostra um pilar localizado em ambiente externo de um bloco de sala de aulas com revestimento em pastilhas cerâmicas, com dimensão na ordem de $10 \times 10 \mathrm{~cm}$ e rejuntamento com largura média de $1 \mathrm{~cm}$.

Observa-se uma sutil diferença de temperatura no revestimento cerâmico desse pilar, na verificação in loco foi encontrado manchas escuras no rejunte indicando a presença lodo. Isso pode representar alguma falha de aderência do revestimento com o substrato, métodos complementares como o teste de percussão (som cavo) e ensaio de arrancamento podem caracterizar melhor essa anomalia. 


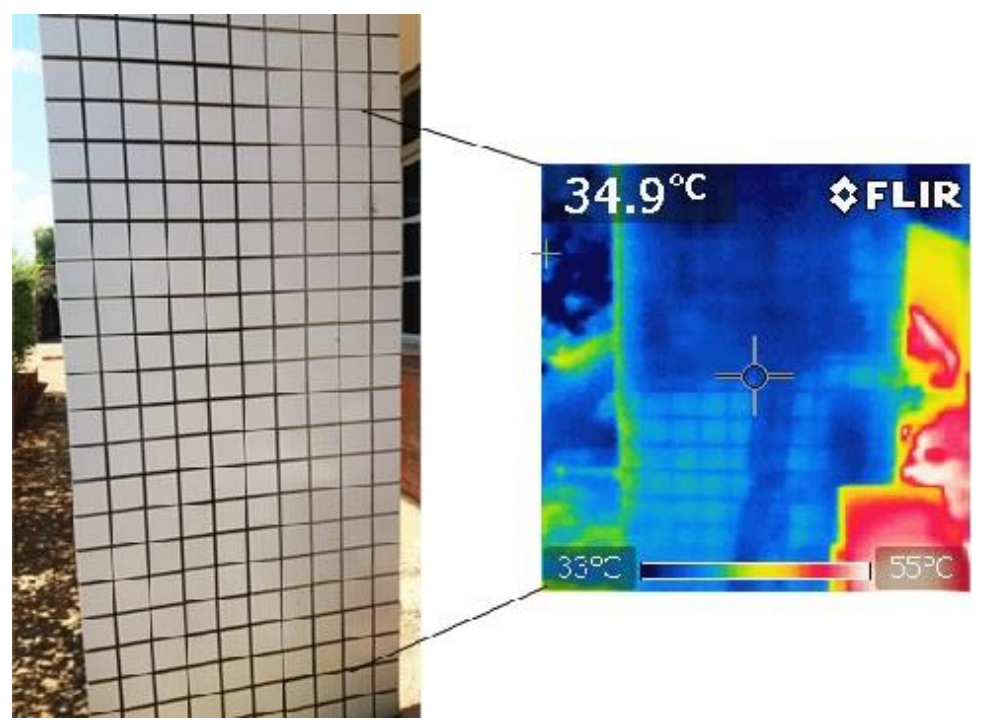

Figura 5: Revestimento cerâmico em pilar externo com anomalias.

\subsection{Umidade em juntas de dilatação estrutural}

Juntas de dilatação são locais bastante propensos a problemas como falhas de vedação, muitas vezes devido a erros de execução ou uso de material inadequado. Na Figura 6 é possível identificar no gradiente de temperatura, que regiões mais frias ocorrem exatamente no local que se encontra a junta de dilatação estrutural desse bloco de uso misto (administrativo e de salas de aulas). A termografia está indicando uma faixa de variação de temperatura na ordem de $6^{\circ} \mathrm{C}$, na região da junta a temperatura é de aproximadamente $+31^{\circ} \mathrm{C}$.

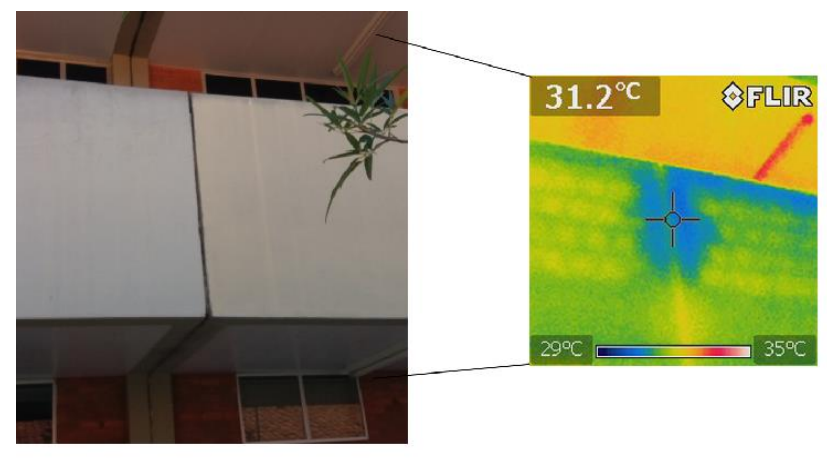

a) Junta de dilatação estrutural - trecho do peitoril no $1^{\circ}$ pav.

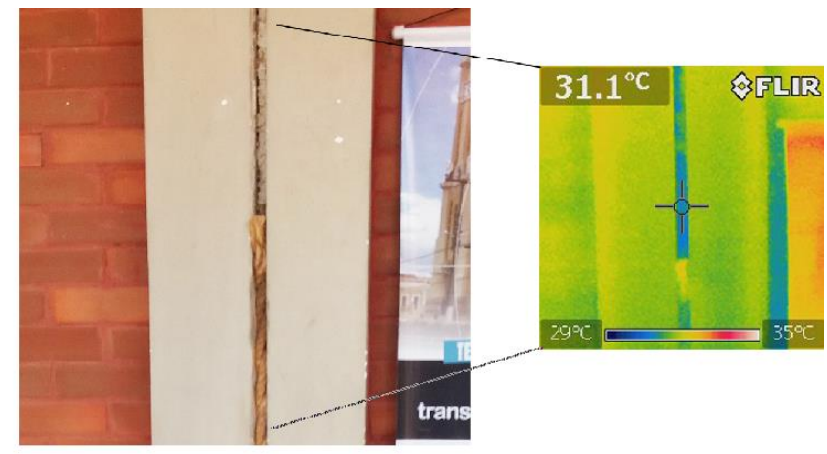

b) Junta de dilatação estrutural - trecho no pav. térreo

Figura 6: Junta de dilatação com falha no sistema de vedação e presença de umidade.

$\mathrm{Na}$ vistoria in-loco nota-se que a junta de dilatação está totalmente irregular, indicando a falta de manutenção a algum tempo. Foi utilizado pedaços de corda como delimitador de profundidade da junta, além disso, o selante utilizado para vedação encontra-se bastante degradado, sendo que, em alguns locais já nem há sua presença. Como a junta percorre toda a largura da edificação, dividindo-a em duas, torna-se um ponto crítico para infiltração de água oriunda da limpeza dos pavimentos superiores bem como das chuvas.

\subsection{Umidade em encontro de alvenarias externas}

Em alguns locais é possível identificar também a presença de umidade em encontros de alvenarias de vedação. Na Figura 7 é mostrado um exemplo dessa situação, a imagem termográfica informa uma faixa de variação de temperatura na ordem de $8^{\circ} \mathrm{C}$. Nota-se a presença de algumas manchas escuras características da manifestação de bolor. A região mais fria, com temperatura na ordem de $+35^{\circ} \mathrm{C}$ ocorre em toda a altura do pilar que está no encontro das alvenarias, com a vistoria in loco não foi possível identificar a possível causa dessa umidade. Nesse caso seria necessária uma intervenção mais detalhada para caracterização completa dessa MP. 


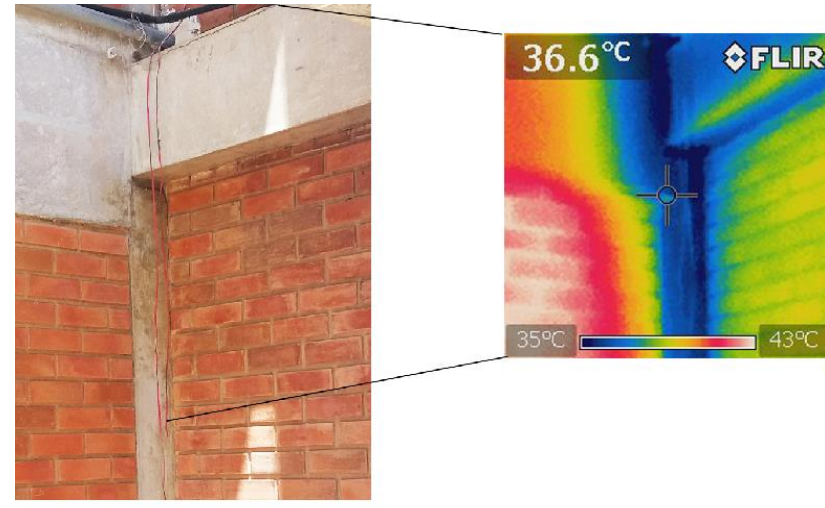

a) Trecho intermediário do encontro de paredes (externas)

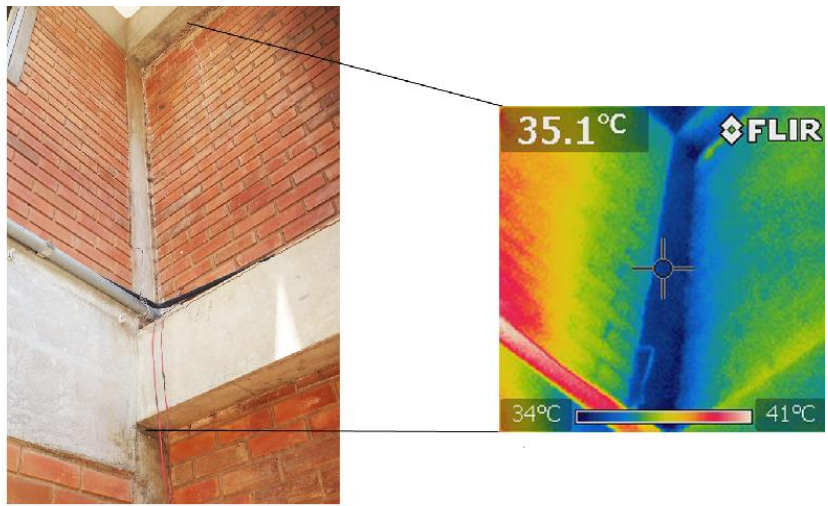

b) Trecho superior do encontro de paredes (externas)

Figura 7: Encontro de alvenarias externas com presença de umidade

\section{CONCLUSÕES}

A TI têm se apresentado como uma técnica de inspeção bastante útil para os profissionais da engenharia de civil. É um ensaio não destrutivo, e por isso, não causa nenhuma modificação nos locais avaliados, além de ser possível utilizá-lo a distância. Traz também, impactos positivos em relação a preservação ambiental, uma vez que, em situações usuais, sem o uso da tecnologia, provavelmente, seria necessária uma intervenção física na edificação maior do que a realmente necessária, o que acabaria por gerar volumes desnecessários de resíduos de demolição.

Com essa ferramenta foi possível localizar pontos com MP nos vários blocos que compõem o conjunto educacional avaliado, sendo que, algumas manifestações apresentam-se em estágio inicial, onde provavelmente apenas profissionais com certa experiencia poderiam fazer a identificação correta do problema. A TI ajuda na estimativa da magnitude da MP, bem como, a possível origem do problema.

É necessário uma avaliação qualitativa e quantitativa das imagens termográficas, uma vez que, as condições ambientes e a configuração do aparelho farão total diferença nos resultados, algumas vezes, pode ser necessário obter várias imagens em horários e climas diferentes, para uma correta percepção do problema. Por exemplo, algumas MPs na construção civil, como a umidade ascendente do solo em alvenarias, são mais fáceis de identificar quando observadas em um dia ensolarado e logo após um período de chuvas, devido ao maior gradiente térmico presente nos materiais.

Nas edificações avaliadas, constatou-se que é possível observar a presença de umidade em alvenarias devido a vários fatores: anomalias em revestimentos cerâmicos (possivelmente com falha na aderência e formação de vazios com umidade), umidade do solo e falhas na estanqueidade de tubulações. Além disso, vale destacar a notável contribuição da TI em outras demandas da construção civil, como por exemplo, auxiliar na localização de elementos estruturais escondidos entre as alvenarias, identificação de falhas de isolamento em ambientes climatizados ou acústicos, além de ser aplicada na avaliação da eficiência térmica em diversos componentes de uma edificação, como por exemplo, sistemas de revestimento de fachada.

Como ferramenta a TI se apresentou bastante eficiente para identificação de anomalias presentes em diversos elementos que compõem uma edificação. Porém, vale destacar que se trata de um ensaio capaz de indicar tão somente a intensidade da irradiação térmica presente naquele local. Com isso, os resultados necessitam da interpretação adequada por parte dos profissionais que fazem uso da técnica, em muitas vezes, será necessário ensaios complementares para a correta identificação do problema, e a calibração do aparelho precisa ser verificada para cada ensaio. 


\section{AGRADECIMENTOS}

Agradecemos ao Instituto Federal de Ciencias e Tecnologia da Paraiba (IFPB) Campus Cajazeiras, por incentivar e tornar possivel a realização e publicação dessa pesquisa.

\section{REFERÊNCIAS}

ASSOCIAÇÃO BRASILEIRA DE NORMAS TÉCNICAS. NBR 15572: Ensaios não destrutivos - Termografia. Rio de Janeiro, 2013.

BARREIRA, E. S. B. Aplicação da termografia ao estudo do comportamento higrotérmico dos edifícios. Dissertação, FEUP. Porto, 2004.

BAUER, E. Condicionantes das medições termográficas para avaliação de temperatura em fachadas. X Simpósio Brasileiro de Tecnologia das Argamassas. Fortaleza, CE, Brasil, 2013.

BAUER, ELTON; PAVÓN, ELIER. Termografia de infravermelho na identificação e avaliação de manifestações patológicas em edifícios. Revista Concreto \& Construções - IBRACON, [s. 1.], ano 2015, ed. 79, p. 93-98, jul. 2015.

BRIOSCHI, M. L. A história da termografia, Instituto de Física de São Carlos, Universidade de São Paulo, 2008.

FLIR SYSTEMS (org.). Manual do utilizador FLIR: Flir i3, i5, i7, Extech IRC30. T559591. ed. rev. Wilsonville, EUA: [s. n.], 2010. 180 p.

IANTAS, L. C. Estudo De Caso: Análise de Patologias estruturais em Edificação de Gestão Pública. Monografia (Curso de Pós-Graduação Construção de Obras Públicas) - Universidade Federal do Paraná, 2010.

KERSUL, G. M. Uso da termografia para inspeções e manutenção predial - estudo de caso. Monografia, UniCEUB, Brasília, 2014.

MENDONÇA, L., AMARAL, M., CATARINO, P. A termografia por infravermelhos como ferramenta para auxílio à inspeção e manutenção dos edifícios. Jornadas de Engenharia de 70 Manutenção. ISEL, 2013.

O. T. TAKEDA, W. MAZER (2018), "Potencial da análise termográfica para avaliar manifestações patológicas em sistemas de revestimentos de fachadas", Revista ALCONPAT, 8 (1), pp. 38 - 50 , DOI: http://dx.doi.org/10.21041/ra.v8i1.181 